\title{
Article
}

\section{Controlling Proton-Coupled Electron Transfer in Bio-Inspired Artificial Photosynthetic Relays}

Emmanuel Odella, S. Jimena Mora, Brian L. Wadsworth, Mioy T. Huynh, Joshua J. Goings, Paul A. Liddell, Thomas L. Groy, Miguel Gervaldo, Leónides E. Sereno, Devens Gust, Thomas A. Moore, Gary F. Moore, Sharon Hammes-Schiffer, and Ana L. Moore J. Am. Chem. Soc., Just Accepted Manuscript • DOI: 10.1021/jacs.8b09724 • Publication Date (Web): 16 Oct 2018 Downloaded from http://pubs.acs.org on October 16, 2018

\section{Just Accepted}

"Just Accepted" manuscripts have been peer-reviewed and accepted for publication. They are posted online prior to technical editing, formatting for publication and author proofing. The American Chemical Society provides "Just Accepted" as a service to the research community to expedite the dissemination of scientific material as soon as possible after acceptance. "Just Accepted" manuscripts appear in full in PDF format accompanied by an HTML abstract. "Just Accepted" manuscripts have been fully peer reviewed, but should not be considered the official version of record. They are citable by the Digital Object Identifier (DOI $\left.{ }^{8}\right)$. "Just Accepted" is an optional service offered to authors. Therefore, the "Just Accepted" Web site may not include all articles that will be published in the journal. After a manuscript is technically edited and formatted, it will be removed from the "Just Accepted" Web site and published as an ASAP article. Note that technical editing may introduce minor changes to the manuscript text and/or graphics which could affect content, and all legal disclaimers and ethical guidelines that apply to the journal pertain. ACS cannot be held responsible for errors or consequences arising from the use of information contained in these "Just Accepted" manuscripts. 


\section{Introduction}

In all water-oxidizing photosynthetic organisms, tyrosine $\mathrm{Z}$ (Tyrz) of photosystem II (PSII) is a high-potential electron transfer relay between the reaction-center chlorophylls (P680) and the oxygen-evolving complex (OEC).1,2 Its role can be described by considering any one of four steps of the electrogenic cycle in which the energy of four photons is used to oxidize two water molecules, yielding $\mathrm{O}_{2}$, four protons, two reduced quinones, and proton-motive force. ${ }^{3,4} \mathrm{~A}$ cycle begins with excitation of the primary donor (P680) to produce $\mathrm{P} 680^{*}$ followed by charge separation involving a nearby chlorophyll (Chl), forming $\mathrm{P} 680^{\circ+}$ and Chl ${ }^{--}$. Subsequent electron transfers yield reduced quinones, resulting in proton uptake from the chloroplast stroma and the generation of proton-motive force. The oxidized primary donor, $\mathrm{P} 680^{\circ}$, is reduced by electron transfer from $\mathrm{Tyr}_{\mathrm{z}}$, which in turn is reduced by the OEC where water oxidation is the ultimate source of electrons. The protons produced upon water oxidation are conducted to the thylakoid lumen where they also contribute to proton-motive force.5,6 Physically positioned and electrochemically poised between P680 and the OEC, Tyrz and its H-bonded partner, His190, serve as the redox relay between $\mathrm{P} 680$ and the OEC. ${ }^{7}$ The oxidation of $\mathrm{Tyr}_{\mathrm{z}}$ by $\mathrm{P} 680^{\circ+}$ illustrates a classic proton-coupled electron transfer (PCET) process in which the oxidation of Tyrz is accompanied by proton transfer to His190.8,9 Moreover, other PCET processes in the extensive $\mathrm{H}$-bond network around the OEC are involved in redox leveling, which is key to removing four electrons from the OEC using a constant potential oxidant, $\mathrm{P} 680^{\bullet+} .10,11$ In addition to oxygenic photosynthesis, PCET processes involving tyrosine and/or histidine residues are ubiquitous in nature. ${ }^{12-17}$

Many artificial systems have been inspired by the structure and function of the Tyrz-His190 pair in PSII, and associated experimental and theoretical studies have contributed to a deeper understanding of the more complex natural process and PCET in general. ${ }^{18-27}$ In particular, benzimidazole phenol (BIP) constructs have been studied as models of the Tyr $_{z}$-His190 pair.28-31 Upon oxidation of the phenol, proton transfer to the benzimidazole occurs, generally perceived as 
an example of a concerted one-electron, one-proton transfer (EPT) process. ${ }^{25}$ Electrochemical measurements show that the phenoxyl radical formed upon oxidation of BIP, $\mathbf{1}$ (Chart 1), which features an intramolecular H-bond between the phenol and the nitrogen at the 3-position of the imidazole, is thermodynamically capable of water oxidation near neutral $\mathrm{pH}^{32}$

Recently, we reported a concerted one-electron, two-proton transfer (E2PT) process associated with the electrochemical oxidation of the phenol in amino-substituted BIPs. ${ }^{7,33}$ Although the theoretical calculations were consistent with a fully concerted E2PT process, the experimental measurements could not distinguish between a fully concerted E2PT process and a stepwise mechanism where an EPT process is followed by an ultrafast second proton transfer, which is viewed as effectively concerted. This process translocates protons over a distance of ca. $7 \AA$ but is accompanied by a decrease in the potential of the phenoxyl radical/phenol redox couple by $\sim 300 \mathrm{mV} .{ }^{33}$ Such a thermodynamic cost in redox potential limits the use of amino-substituted BIPs as redox mediators in water oxidation processes. However, theoretical calculations predicted that BIPs bearing substituents with reduced $\mathrm{p} K_{\mathrm{a}}$ 's such as imines, which can be substituted to tune their $\mathrm{p} K_{\mathrm{a}}$ 's, would undergo E2PT processes that maintain a considerably higher potential for the phenoxyl radical/phenol redox couple. ${ }^{33}$ Herein, new models of the Tyrz-His190 pair composed of benzimidazole phenol imine derivatives (BIP-Ph ${ }^{\mathrm{R} i m i n e s}$ 2-8, Chart 1) are reported. Substitutions at the para-position of the aniline ring of BIP-PhRimines modulate the driving force for the second proton transfer due to interrelated factors that include the $\Delta \mathrm{p} K_{\mathrm{a}}$ between the benzimidazolium ion and the protonated imine, the internal H-bond strength between the $1 \mathrm{H}$-benzimidazole proton and the imine nitrogen lone pair, and the midpoint potential of the phenoxyl radical/phenol couple. These parameters control the observed ratio of the EPT and E2PT products.

Chart 1. Molecular Structures of BIP and Derivatives Substituted at the 7-Position. On the Right Products of Electrochemical Oxidation of the Phenol Coupled with One-Proton Transfer (EPT) and Two-Proton Transfers (E2PT)
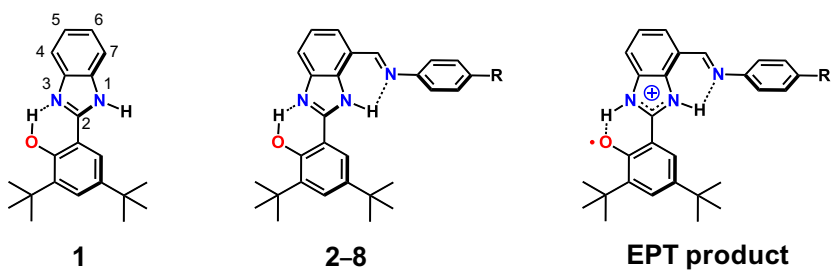

$$
\begin{aligned}
& 2-\mathrm{R}=\mathrm{CN} \quad \mathrm{BIP}-\mathrm{Ph}^{\mathrm{CN}} \text { imine } \\
& 3-\mathrm{R}=\mathrm{CF}_{3} \quad \mathrm{BIP}-\mathrm{Ph} \mathrm{CF}_{3 \text { imine }} \\
& 4-\mathrm{R}=\mathrm{Cl} \quad \mathrm{BIP}-\mathrm{Ph}^{\mathrm{Cl}} \text { imine } \\
& 5-\mathrm{R}=\mathrm{H} \quad \text { BIP-Ph }{ }^{\mathrm{H}} \text { imine } \\
& 6-\mathrm{R}=\mathrm{CH}_{3} \quad \text { BIP-Ph }{ }^{\mathrm{CH}_{3}} \text { imine } \\
& 7-\mathrm{R}=\mathrm{OCH}_{3} \quad \text { BIP-Ph }{ }^{\mathrm{OCH}_{3}} \text { imine } \\
& 8-\mathrm{R}=\mathrm{N}\left(\mathrm{CH}_{3}\right)_{2} \quad \mathrm{BIP}-\mathrm{Ph}^{\mathrm{N}\left(\mathrm{CH}_{3}\right)_{2} \text { imine }}
\end{aligned}
$$

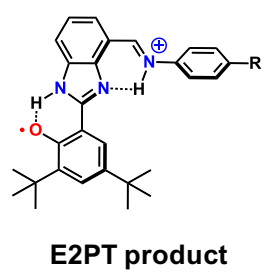

Theoretical: The optimized geometries, energies, and vibrational frequencies were calculated with density functional theory (DFT) using the B3LYP34-37 functional and the 6-31G** basis set. ${ }^{38,39}$ Solvent effects were included using the conductor-like polarizable continuum model. ${ }^{40,41}$ These calculations were performed with the Gaussian 09 program. ${ }^{42}$ Further computational details are provided in the Supporting Information, SI.

\section{Experimental:}

Synthesis: Substituted BIP-Ph ${ }^{\mathrm{R} i m i n e s}$ (Chart 1) were synthesized according to a standard procedure with methyl 2,3-diaminobenzoate and 3,5-di-tert-butyl-2-hydroxybenzaldehyde as starting materials for the Philipps-Ladenburg reaction that yielded $\mathrm{BIP}-\mathrm{COOCH}_{3}{ }^{43-45}$ The $\mathrm{BIP}-\mathrm{COOCH}_{3}$ was reduced with $\mathrm{LiAlH}_{4}$ to give the corresponding $\mathrm{BIP}-\mathrm{CH}_{2} \mathrm{OH}$. Oxidation of $\mathrm{BIP}-\mathrm{CH}_{2} \mathrm{OH}$ with activated $\mathrm{MnO}_{2}$ generated the BIP-CHO. The BIP-Ph ${ }^{\mathrm{R} i m i n e s}$ were prepared following an established method for the synthesis of aldimines from aniline derivatives in the presence of pyrrolidine as a catalyst. 46 The complete synthetic procedure and NMR characterization are provided in the SI.

Crystal Structure Determination: Crystals of BIP$\mathrm{Ph}^{\mathrm{OCH}_{3}}$ imine 7 were grown by the vapor diffusion technique using $\mathrm{CH}_{2} \mathrm{Cl}_{2}$ and hexane as solvents. A Bruker Smart APEX diffractometer was used to obtain single crystal diffraction data. Detailed information of crystallographic structure and data collections are provided in the SI.

Cyclic voltammetry: Cyclic voltammetry measurements were performed with a Biologic potentiostat using a glassy carbon (3 mm diameter) working electrode, a Pt wire counter electrode, and a Ag wire pseudoreference electrode in a conventional three-electrode cell. All cyclic voltammograms (CVs) were collected in anhydrous $\mathrm{CH}_{3} \mathrm{CN}$ or $\mathrm{CH}_{2} \mathrm{Cl}_{2}$, previously distilled and kept over molecular sieves and $\mathrm{K}_{2} \mathrm{CO}_{3}$, containing the compound of interest at a concentration of 1 $\mathrm{mM}$. Tetrabutylammonium hexafluorophosphate TBAPF $_{6}$, $0.5 \mathrm{M}$ in $\mathrm{CH}_{3} \mathrm{CN}$ and 0.1 in $\mathrm{CH}_{2} \mathrm{Cl}_{2}$ ) was used as the supporting electrolyte, and the scan rate was $100 \mathrm{mV} \mathrm{s}^{-1}$. All measurements were conducted at room temperature under an argon atmosphere. The argon gas stream was pre-saturated by bubbling through the organic solvent used for the experiments in a separate Schlenk flask and let into the electrochemical cell via PEEK tubing. The glassy carbon working electrode was polished between measurements with an aluminum slurry on a microcloth polishing pad, followed by solvent rinses and drying under a stream of nitrogen. The potential of the pseudoreference electrode was determined using the ferrocenium/ferrocene redox couple as an internal standard and adjusting to the saturated calomel electrode (SCE) scale (with $E_{1 / 2}$ taken to be $0.40 \mathrm{~V} v s$ SCE in $\mathrm{CH}_{3} \mathrm{CN}$ and $0.46 \mathrm{~V}$ vs SCE in $\mathrm{CH}_{2} \mathrm{Cl}_{2}$ ). ${ }^{47}$

FTIR and Infrared Spectroelectrochemistry (IRSEC): FTIR measurements were performed using a Bruker Vertex 70 spectrometer in absorption mode under a dry nitrogen purge with a $2 \mathrm{~cm}^{-1}$ resolution, GloBar MIR source, broadband $\mathrm{KBr}$ beamsplitter, and liquid nitrogen cooled MCT detector. Spectra were collected (64 scans) in anhydrous $\mathrm{CH}_{2} \mathrm{Cl}_{2}$ (distilled over $\mathrm{CaH}_{2}$ and kept over molecular sieves and $\mathrm{K}_{2} \mathrm{CO}_{3}$ ) at a concentration of $19 \mathrm{mM}$, and $0.1 \mathrm{M} \mathrm{TBAPF}_{6}$ was used to simulate the conditions of the IRSEC measurements (vide infra). Because the molecules containing the imine linkage are susceptible to hydrolysis, care was taken 
to minimize the presence of moisture, and the compounds were dried under high vacuum overnight before use. The FTIR spectra were obtained using a $\mathrm{CaF}_{2}$ liquid transmission cell (International Crystal Laboratories, Model SL-3, path length: $0.1030 \mathrm{~mm}$ ), and the $\mathrm{CF}_{3} \mathrm{COOH}$ added to the cell was distilled before use.

IRSEC measurements were conducted using a Biologic potentiostat connected to an optically transparent thin-layer electrochemical cell (Spectroelectrochemistry Reading RT OTTLE cell), pathlength $0.2 \mathrm{~mm}$, equipped with $\mathrm{CaF}_{2}$ optical windows. The cell contained a Pt mesh counter electrode, a Ag wire pseudoreference electrode, and a Pt mesh working electrode. The Pt mesh working electrode was positioned in the light path of the IR spectrophotometer. For all IRSEC measurements, the compounds were used at a concentration of $19 \mathrm{mM}$, with $0.1 \mathrm{M} \mathrm{TBAPF}_{6}$ as the supporting electrolyte. The cell and its contents were sealed under an argon atmosphere prior to all measurements, and thin layer constant potential electrolysis was monitored via FTIR as the working electrode was polarized positive in $50-100 \mathrm{mV}$ increments $v s$ the silver wire reference. Absorption spectra were continuously collected at each applied potential until there were no further significant changes. This procedure was repeated until increasing the polarization no longer resulted in significant changes of the spectra ${ }^{48,49}$ and the broad IR absorption at $\sim 2,700 \mathrm{~cm}^{-1}$ characteristic of the phenol $\mathrm{OH}$ was no longer observable, ${ }^{18}$ confirming depletion of the phenol within the path of the optical probe. Under these conditions it is assumed the total concentration of oxidized products $([\mathrm{EPT}]+[\mathrm{E} 2 \mathrm{PT}])$ is approximately equal to the initial concentration of the BIP- $\mathrm{Ph}^{\mathrm{R}}$ imine solution. Using this concentration, and the observation that the EPT product is not detected in the IRSEC of 7, an extinction coefficient of $467 \mathrm{M}^{-1} \mathrm{~cm}^{-1}$ for the band at $1652 \mathrm{~cm}^{-1}$ was estimated. This band was assigned to the protonated imine stretching mode characteristic of the E2PT product.

KIE measurements: All measurements were carried out at $20{ }^{\circ} \mathrm{C}$ in a conventional three-electrode cell using a Pt counter electrode, an Ag wire as pseudo-reference electrode, and a glassy carbon working electrode (1 mm diameter). Anhydrous $\mathrm{CH}_{3} \mathrm{CN}$, kept over molecular sieves and $\mathrm{K}_{2} \mathrm{CO}_{3}$, was used as the solvent, with $0.5 \mathrm{M} \mathrm{TBAPF}_{6}$ as the supporting electrolyte. Concentrations in the 3.3 to $4.7 \mathrm{mM}$ range of the $\mathrm{BIP}-\mathrm{Ph}^{\mathrm{R}}$ iminines were used. All of the CVs were corrected for ohmic effects using feedback techniques. The baseline currents were registered for each scan rate under the same experimental conditions $\left(\mathrm{CH}_{3} \mathrm{CN}\right.$ containing only supporting electrolyte without the addition of the studied molecule) and were subtracted from the corresponding CVs before processing. Redox potentials were calculated as the mean of the anodic and cathodic peaks. After each electrochemical measurement, ferrocene was added to the solution and the potential of the pseudo-reference electrode was determined. In order to calculate the KIE for each compound, the apparent standard rate constants of electron transfer $\left(k_{a p p}\right)$ were determined in $\mathrm{CH}_{3} \mathrm{CN}+2 \% \mathrm{CH}_{3} \mathrm{OH}$ and $\mathrm{CH}_{3} \mathrm{CN}+2 \%$ $\mathrm{CH}_{3} \mathrm{OD}$ by the Nicholson's method. ${ }^{50,51} \mathrm{CVs}$ were taken at different scan rates between 0.25 and $200 \mathrm{~V} / \mathrm{s}$, and the difference between the potentials of the anodic and cathodic peaks $\left(\Delta E_{\mathrm{p}}\right)$ was calculated for each scan rate $v . \Delta E_{\mathrm{p}}$ is related to the dimensionless parameter $\psi, 50,51$ which is linked to $k_{a p p}$ and $v$ according to the following equation:

$$
\mathrm{k}_{\mathrm{app}}=\psi\left(\frac{\pi \mathrm{D}_{\mathrm{O}} \mathrm{Fv}}{\mathrm{RT}}\right)^{1 / 2}\left(\frac{\mathrm{D}_{\mathrm{R}}}{\mathrm{D}_{\mathrm{O}}}\right)^{\alpha / 2}
$$

where $\alpha$ is the transfer coefficient (taken as 0.5 ), and $D_{R}$ and $D_{o}$ are the diffusion coefficients $\left(\mathrm{cm}^{2} \mathrm{~s}^{-1}\right)$ for the oxidized and reduced forms, which were assumed to be the same value of $1 \times 10^{-5} \mathrm{~cm}^{2} \mathrm{~s}^{-1}$. Thus, Equation (1) can be written as follows:

$$
\psi=\mathrm{k}_{\mathrm{app}}\left(\frac{\pi \mathrm{D}_{\mathrm{O}} \mathrm{Fv}}{\mathrm{RT}}\right)^{-1 / 2}
$$

The value of $k_{\text {app }}$ can be obtained from the slope of a plot of $\psi v s v^{-1 / 2}$ (Figure S39). The values of $k_{a p p}$ are between $\sim 2 \times 10^{-2}$ and $\sim 8 \times 10^{-2} \mathrm{~cm} \mathrm{~s}^{-1}$ (Table S13). CVs were simulated (Figures S40 and S41) with DigiSim 2.1 software using the corresponding kapp values shown in Table S13.

\section{Results and Discussion}

Structural Characterization. The crystal structure of $\mathbf{7}$ (Figure 1) indicates a nearly planar molecular framework with a dihedral angle between the phenol and benzimidazole moieties of $3.4^{\circ}$. The $0-\mathrm{N}$ distance of $2.57 \AA$ is in agreement with a strong $\mathrm{H}$-bond between the phenolic proton and the nitrogen lone pair of benzimidazole. ${ }^{18,33,44}$ The crystal structure also indicates a H-bond between the $1 \mathrm{H}$-benzimidazole proton and the imine nitrogen, with an N-N distance of $2.92 \AA$ (Figure 1).
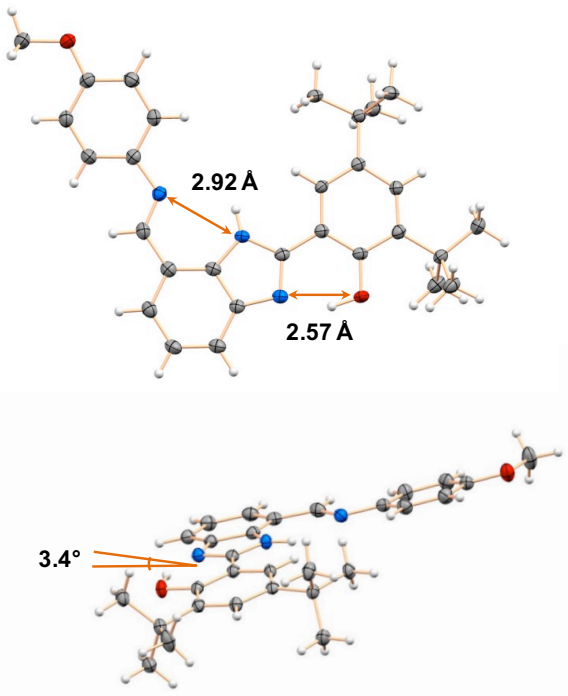

Figure 1. ORTEP representations of the crystal structure of $\mathrm{BIP}-\mathrm{Ph}^{\mathrm{OCH}_{3}}$ imine 7. The upper Figure shows the distances between the atoms involved in both H-bonds. The lower Figure shows the dihedral angle between the phenol and benzimidazole moieties. Carbons are shown in gray, oxygens in red, nitrogens in blue, and hydrogens in white. Thermal ellipsoids are drawn at the $50 \%$ probability level.

The crystallographic data of $\mathbf{7}$ are in good agreement with the optimized structure determined from DFT calculations (Table S14 and Figure S42), and similar structures were obtained by geometrical and energy optimization of 2-6 and 8. Additional support for the formation of a strong H-bond between the $1 \mathrm{H}$-benzimidazole proton and the imine nitrogen is obtained from IR (see IRSEC section) and NMR data. 
Analysis of the ${ }^{1} \mathrm{H}$ NMR spectra for compounds 2-8 confirms the presence of the two internal H-bonds (Figure 2 and Table 1) in $\mathrm{CDCl}_{3}$ solutions of all samples. There is slight variation in the $\mathrm{OH}$ chemical shift, $\delta_{\mathrm{OH}}$, in the BIP$\mathrm{Ph}^{\mathrm{R} i m i n e s}$ when varying the para-substituent of the $N$-phenylimine moiety. The substitution with electron-donating groups results in downfield shifts. ${ }^{33}$ The formation of the $\mathrm{H}$ bond between the $1 H$-benzimidazole proton and the imine nitrogen is evident by the NMR chemical shift of the NH group of benzimidazole $\left(\delta_{\mathrm{NH}}\right)$. In all BIP-Ph ${ }^{\mathrm{R}}$ imines, the $\delta_{\mathrm{NH}}$ is found between $\sim 11.48-11.98 \mathrm{ppm}$, downfield from the equivalent $\mathrm{NH}$ in $\mathbf{1}$ (9.34 ppm) and $N$-diethylaminoBIP (11.17 ppm), in $\mathrm{CDCl}_{3 .}{ }^{33}$

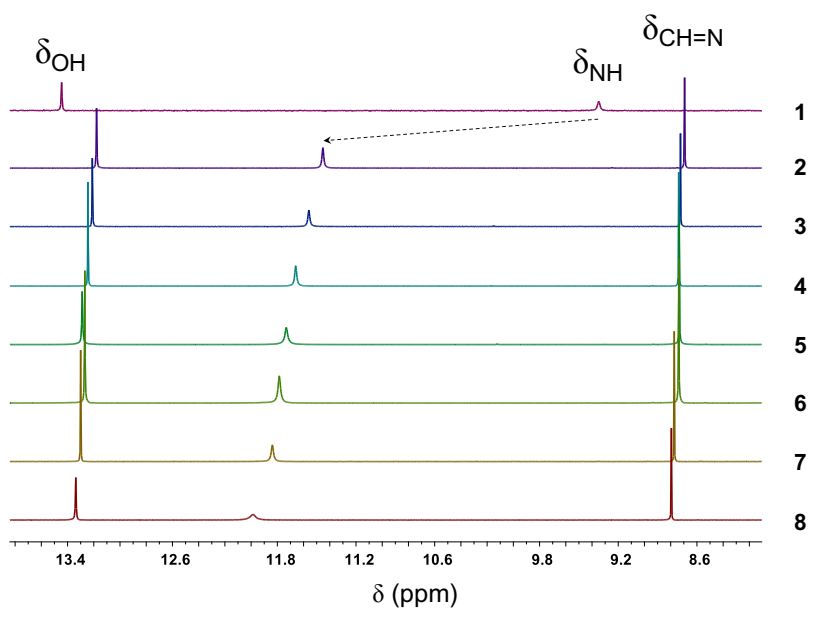

Figure 2. $400 \mathrm{MHz}{ }^{1} \mathrm{H}$ NMR spectra in $\mathrm{CDCl}_{3}$ of BIP derivatives showing the $\delta_{\mathrm{OH}}, \delta_{\mathrm{NH}}$ and $\delta_{\mathrm{CH}=\mathrm{N}}$. The ${ }^{1} \mathrm{H}$ NMR spectrum of 1 is included for comparison.

Table 1. ${ }^{1} \mathrm{H}$ NMR Chemical Shifts of BIP Derivatives (Chart 1) and Hammett Constants $\left(\sigma_{p}\right)$ for the Corresponding Substituent Groups ${ }^{a}$

\begin{tabular}{|c|c|c|c|c|}
\hline \multirow{2}{*}{ Compound } & \multicolumn{3}{|c|}{ Chemical Shift (ppm) } & \multirow{2}{*}{$\sigma_{\mathrm{p}^{b}}$} \\
\hline & $\delta_{\mathrm{NH}}$ & $\delta_{\mathrm{OH}}$ & $\delta_{\mathrm{CH}=\mathrm{N}}$ & \\
\hline 1: BIP & 9.34 & 13.45 & $\mathrm{~N} / \mathrm{A}$ & $\mathrm{N} / \mathrm{A}$ \\
\hline 2: $\mathrm{BIP}-\mathrm{Ph}^{\mathrm{CN}}$ imine & 11.48 & 13.19 & 8.72 & 0.66 \\
\hline 3: $\mathrm{BIP}-\mathrm{Ph}^{\mathrm{CF}_{3}}$ imine & 11.58 & 13.21 & 8.74 & 0.54 \\
\hline 4: $\mathrm{BIP}-\mathrm{Ph}^{\mathrm{Cl}}$ imine & 11.66 & 13.23 & 8.74 & 0.23 \\
\hline 5: $\mathrm{BIP}-\mathrm{Ph}^{\mathrm{H}}$ imine & 11.76 & 13.21 & 8.76 & 0 \\
\hline 6: $\mathrm{BIP}-\mathrm{Ph}^{\mathrm{CH}_{3}}$ imine & 11.82 & 13.30 & 8.78 & -0.17 \\
\hline 7: $\mathrm{BIP}-\mathrm{Ph}^{\mathrm{OCH}_{3}}$ imine & 11.84 & 13.30 & 8.77 & -0.27 \\
\hline 8: $\mathrm{BIP}-\mathrm{Ph}^{\mathrm{N}\left(\mathrm{CH}_{3}\right)_{2} \text { imine }}$ & 11.98 & 13.34 & 8.79 & -0.83 \\
\hline
\end{tabular}

In the structure of the BIP-Ph ${ }^{\mathrm{R} i m i n e s}$ (see Chart 1) the benzene ring in the benzimidazole moiety is connected with a second para-substituted phenyl ring through the transimine linkage. This structure falls under the widely studied class of benzylideneanilines. ${ }^{53-57}$ Specifically, for para- monosubstituted benzylideneanilines, where the substitution is on the aniline ring, the base strength of the imine nitrogen is influenced by inductive and resonance effects of the substituent. ${ }^{58}$

The substituent effect on the $\mathrm{H}$-bond between the $\mathrm{NH}$ of the imidazole and the nitrogen of the imine in compounds 2-8 can clearly be observed in the series of ${ }^{1} \mathrm{H}$ NMR spectra presented in Figure 2. The $\delta_{\mathrm{NH}}$ moves downfield when electron-withdrawing groups at the para-position of the $\mathrm{N}$-phenylimine moiety are replaced by electron-donating groups, such as the methoxy or $\mathrm{N}$-dimethylamino groups present in compounds $\mathbf{7}$ and $\mathbf{8}$, respectively. As expected, electron-donating substituents increase the electron density at the imine nitrogen, resulting in a stronger $\mathrm{H}$-bond with the $\mathrm{NH}$ of the imidazole. ${ }^{59} \mathrm{~A}$ graph of $\delta_{\mathrm{NH}}$ values against the Hammett substituent constants $\left(\sigma_{\mathrm{p}}\right)$ exhibits a linear correlation for imines 2-8 (Figure S29). Conversely, the azomethine ${ }^{1} \mathrm{H}$ NMR chemical shift $\left(\delta_{\mathrm{CH}=\mathrm{N}}\right)$ appears at $\sim 8.75 \mathrm{ppm}$ and remains essentially constant in all BIP- $\mathrm{Ph}^{\mathrm{R}}$ imines studied (Table 1), as indicated by the absence of a Hammett correlation (Figure S29). This observation is consistent with findings regarding analogous monosubstituted benzylidenanilines. ${ }^{59,60}$

The unsymmetrical nature of BIPs substituted at the 7-position, as in 2-8, leads to two isomeric forms resulting from tautomerization of the imidazole and rotation around the bond between the benzimidazole and phenolic moiety. Only one of these isomers has the appropriate internal $\mathrm{H}$-bond network necessary for the E2PT process (Chart 1), wherein the phenolic $\mathrm{OH}$ group is $\mathrm{H}$-bonded to the benzimidazole nitrogen and a second $\mathrm{H}$-bond is present between the $1 \mathrm{H}$-benzimidazole proton and the imine nitrogen. From ${ }^{1} \mathrm{H}$ NMR, the ratio of isomers is approximately 1:0.1 and 1:0.2 in $\mathrm{CD}_{3} \mathrm{CN}$ and $\left(\mathrm{CD}_{3}\right)_{2} \mathrm{CO}$, respectively. The presence of the two isomers cannot be detected in non-polar solvents such as $\mathrm{CD}_{2} \mathrm{Cl}_{2}$ or $\mathrm{CDCl}_{3}$ (Figure $\mathrm{S} 30$ ).

Electrochemical Studies. Table 2 presents the experimentally obtained midpoint potential for the phenoxyl radi$\mathrm{cal} /$ phenol couple for each of the BIP-Ph ${ }^{\mathrm{R}}$ imines and the calculated values associated with this couple for both EPT and E2PT products in $\mathrm{CH}_{3} \mathrm{CN}$. While theory yields two $E_{1 / 2}$ values for each of the compounds studied, the CVs do not resolve the two redox waves. It is necessary to analyze the IRSEC data to clearly differentiate between the $E_{1 / 2}$ values for oxidation leading to EPT and E2PT products (vide infra). Comparison of the redox waves observed in CVs of 7 with the redox characteristics of reference compounds lacking the phenolic $\mathrm{OH}$ group (BI-Ph ${ }^{\mathrm{OCH}_{3}}$ imine) and $\mathrm{N}$-benzylidene- $p$-anisidine (see synthetic procedure and structures on pages S9-S13), both of which exhibit chemically irreversible oxidation waves at $1.3 \mathrm{~V}$ vs SCE, provides strong evidence that the observed quasi-reversible redox wave in the cyclic voltammogram of $\mathbf{7}$ at $0.93 \mathrm{~V} v s$ SCE corresponds to the oxidation of the phenol moiety (Figure $3 \mathbf{A}$ ). The CVs of compounds 2, 4 and 7 (Figure 3 B) are quasi-reversible with a peak-to-peak separation of $\sim 60 \mathrm{mV}$ (see SI Table S11 for further information regarding electrochemical and chemical reversibility). The CVs for BIP- $\mathrm{Ph}^{\mathrm{R} i m i n e s} \mathbf{3}, \mathbf{5}$, and 6 are shown in the SI (Figure S32). The CVs of 2, 3, 4 and 7 in $\mathrm{CH}_{2} \mathrm{Cl}_{2}$ exhibit similar characteristics (see SI Figure S34 and Table S12). In general, phenoxyl radical/phenol redox 
couples are notoriously irreversible, both electrochemically and chemically. ${ }^{7}$ However, the quasi-reversible electrochemistry associated with compounds 1-7 is almost certainly attributable to the structure, which constrains the proton to an internal $\mathrm{H}$-bond between the phenolic $\mathrm{OH}$ and nitrogen at the 3-position of the benzimidazole. The chemical reversibility of compounds $2-7$ in $\mathrm{CH}_{2} \mathrm{Cl}_{2}$ is $>92 \%$ at relatively slow scan rates $(100 \mathrm{mV} / \mathrm{s})$. Importantly, the midpoint potentials assigned to the phenoxyl radical/phenol couple of these BIP-Ph ${ }^{\mathrm{R} i m i n e s}$ derivatives decrease by less than $\sim 40 \mathrm{mV}$ relative to 1 , instead of the $\sim 300 \mathrm{mV}$ decrease observed for the amino-substituted BIPs. 33

Table 2. Experimental and Calculated Redox Potentials for the BIP-Ph ${ }^{\mathrm{R} i m i n e}$ Constructs ${ }^{a}$

\begin{tabular}{|c|c|c|c|}
\hline \multirow[b]{2}{*}{ Compound } & \multicolumn{3}{|c|}{$E_{1 / 2}(\mathrm{~V} v s \mathrm{SCE})$} \\
\hline & Experimental & $\begin{array}{l}\text { Calculated } \\
\text { for E2PT } b\end{array}$ & $\begin{array}{l}\text { Calculated } \\
\text { for EPT } c\end{array}$ \\
\hline 2: $\mathrm{BIP}-\mathrm{Ph}^{\mathrm{CN}}$ imine & 0.99 & 1.06 & 1.04 \\
\hline 3: $\mathrm{BIP}-\mathrm{Ph}^{\mathrm{CF}_{3}}$ imine & 0.99 & 1.06 & 1.05 \\
\hline 4: $\mathrm{BIP}-\mathrm{Ph}^{\mathrm{Cl}}$ imine & 0.97 & 1.02 & 1.04 \\
\hline 5: $\mathrm{BIP}-\mathrm{Ph}^{\mathrm{H}}$ imine & 0.95 & 0.98 & 1.04 \\
\hline 6: $\mathrm{BIP}-\mathrm{Ph}^{\mathrm{CH}_{3}}$ imine & 0.93 & 0.95 & 1.02 \\
\hline 7: $\mathrm{BIP}-\mathrm{Ph}^{\mathrm{OCH}_{3}}$ imine & 0.93 & 0.93 & 1.00 \\
\hline 8: $\mathrm{BIP}-\mathrm{Ph}^{\mathrm{N}\left(\mathrm{CH}_{3}\right)_{2} \text { imine }}$ & $0.68^{d}$ & - & - \\
\hline
\end{tabular}

${ }^{a}$ The values reported herein were experimentally measured and calculated in $\mathrm{CH}_{3} \mathrm{CN}$. The calculated spin density associated with the unpaired electron in the oxidized species is localized on the phenol group for all compounds studied except $\mathbf{8}$, for which it is localized predominantly on the dimethylaminophenyl moiety (Figure S45).

${ }^{b}$ The potential for $\mathbf{7}$ in $\mathrm{CH}_{3} \mathrm{CN}$ was used as the reference for all calculated potentials associated with an E2PT product, and therefore it agrees with the experimental value by construction.

${ }^{c}$ These potentials were calculated using a thermodynamic scheme that takes into account the E2PT reference reaction as well as the $\Delta G^{0}$ associated with the EPT-E2PT equilibrium. The thermodynamic schemes and relevant equations are provided in the SI (pages S74-S76). The resulting potential for $\mathbf{7}$ served as the reference for all of the EPT reactions. Note that the $\Delta G^{0}$ value used for the reference was the experimentally determined value obtained in $\mathrm{CH}_{2} \mathrm{Cl}_{2}$. However, the difference between the experimentally measured potential for $\mathbf{7}$ in $\mathrm{CH}_{2} \mathrm{Cl}_{2}$ and $\mathrm{CH}_{3} \mathrm{CN}$ is small (less than $0.02 \mathrm{~V}$, Table S12) and the difference between the calculated $\Delta G^{0}$ values in $\mathrm{CH}_{2} \mathrm{Cl}_{2}$ and $\mathrm{CH}_{3} \mathrm{CN}$ is also small (less than $1 \mathrm{kcal} / \mathrm{mol}$, Table S19), so the impact of this treatment is negligible.

${ }^{d}$ This potential corresponds to redox chemistry associated with the $p$ - $N$-dimethylamino group of $\mathbf{8}$ and electrochemical measurements performed using reference compounds support this assignment (Figure S33).

Furthermore, the progressive shift of the midpoint potentials to more positive values is correlated with the increase of the electron-withdrawing strength of the group at the para-position of the $\mathrm{N}$-phenylimine moiety. A plot of the experimental $E_{1 / 2}$ values against the Hammett constants ( $\sigma_{\mathrm{p}}$, Figure 4) shows a characteristic Hammett relationship with the electronic effect of the substituents, even though the distance between the phenol group and the substituents is considerable $(\sim 12 \AA)$. As can be seen from the data presented in Table 2 and Figure 4, the difference between the calculated midpoint potentials for forming EPT and E2PT products are largest with electron-donating groups. Furthermore, the two calculated values of $E_{1 / 2}$ cross over when the electron-withdrawing groups $\left(-\mathrm{CF}_{3}\right.$ and $\left.-\mathrm{CN}\right)$ are present, such that the $E_{1 / 2}$ associated with the E2PT process becomes more positive than the $E_{1 / 2}$ associated with the EPT process. This observation is consistent with the equilibrium constant for [E2PT]/[EPT] changing from $>1$ to $<1$ (vide infra) between compounds $\mathbf{4}$ and $\mathbf{3}$ (Table $\mathbf{3}$ ).
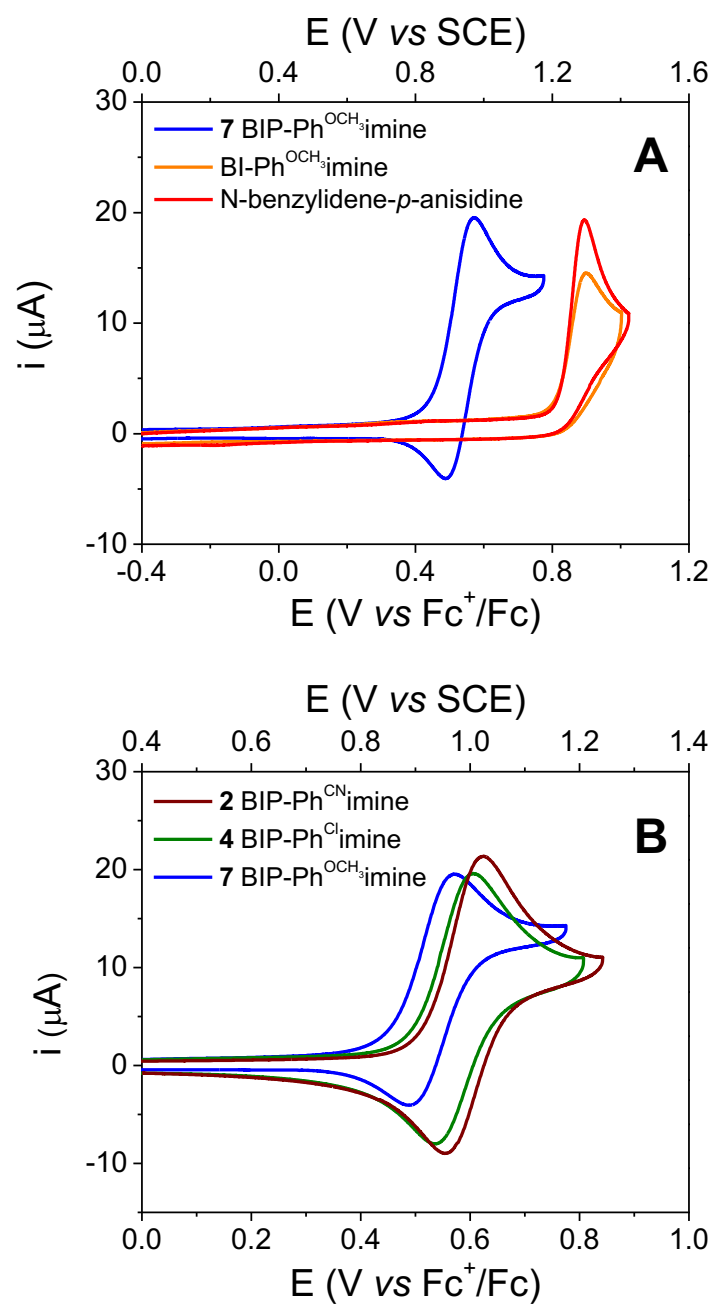

Figure 3. (A) CVs of BIP- $\mathrm{Ph}^{\mathrm{OCH}_{3}}$ imine 7 , a reference compound without the phenolic $\mathrm{OH}$ group $\mathrm{BI}-\mathrm{Ph}{ }^{\mathrm{OCH}_{3}}$ imine, and $N$-benzylidene- $p$-anisidine. (B) CVs of compounds 2, 4 and 7. Concentration: $1 \mathrm{mM}$ of the indicated BIPs and reference compounds, 0.5 $\mathrm{M} \mathrm{TBAPF}_{6}$ supporting electrolyte in dry $\mathrm{CH}_{3} \mathrm{CN}$. WE: glassy carbon. Pseudo RE: Ag wire (ferrocene as internal reference). CE: Pt wire. Scan rate, $100 \mathrm{mV} / \mathrm{s}$.

Infrared Spectroelectrochemical Studies. Experimental evidence for the formation of both EPT and E2PT products was obtained from the IRSEC measurements. As shown previously, distinct structural changes accompanying proton transfer(s) upon oxidation of phenols can be detected by 
this technique. ${ }^{33}$ In the case of BIP-PhRimines, the IRSEC experiments take advantage of the well-established imine and protonated imine infrared spectra in which the $\mathrm{C}=\mathrm{N}$ vibrational stretching mode is sensitive to the local protonation state of the nitrogen. ${ }^{56,61-68}$

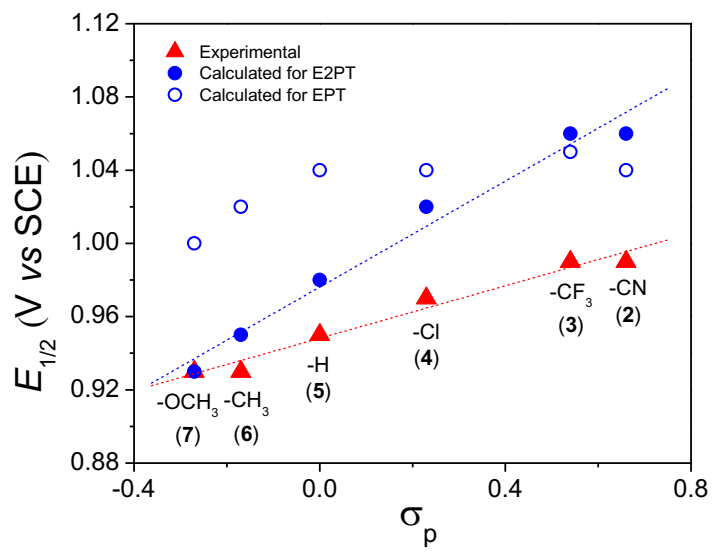

Figure 4. Calculated midpoint potentials $\left(E_{1 / 2}\right)$ for phenoxyl radical/phenol couples of the $\mathrm{BIP}-\mathrm{Ph}^{\mathrm{R} i m i n e s}$ when undergoing an $(0)$ EPT or $(\bullet)$ E2PT process in $\mathrm{CH}_{3} \mathrm{CN}$, and the associated experimental $(\Delta)$ values $v s$ Hammett constants $\left(\sigma_{\mathrm{p}}\right)$. The calculated $E_{1 / 2}$ value for the E2PT of 7 is the same as the experimental value by construction. Linear fits to the experimental data and calculated values for the E2PT process are shown with dash lines ( $R=0.96$ and $R=0.97$, respectively). The substituents at the para-position of the $N$-phenylimine group of 2-7 are shown.

Figure 5 A, B and $\mathbf{C}$ show the IRSEC spectra for the BIP$\mathrm{Ph}^{\mathrm{R}}$ imines 2, 4 and 7, respectively, in the $1700-1400 \mathrm{~cm}^{-1}$ region. IRSEC spectra of $\mathbf{3}$ are shown in the SI (Figure S35). As described above, IR spectra were obtained as a function of applied potential, and the potentials were held constant until no further changes in the collected FTIR spectra were observed. Significant changes in the absorbance and band positions are indicated with arrows. As shown in Figure 5 A, B and C, a new band appears at $1652 \mathrm{~cm}^{-1}$ for 2, 4 and 7 under applied potential. However, the relative intensity of this band is different in the three samples and is most pronounced in the case of 7 . This band has a large component of the protonated imine group stretching $\left(\mathrm{v}_{\mathrm{C}=\mathrm{NH}^{+}}\right)$and is evidence that two proton transfers take place upon oxidation of the phenol (an E2PT product). ${ }^{56,65-67}$ The DFT normalmode analysis of 7 supports these assignments (see Figure S46). In control experiments, the appearance of this band in 7 was also detected when the molecule was treated with $\mathrm{CF}_{3} \mathrm{COOH}$ (see Figure S36). On the other hand, the appearance of the band at $1556 \mathrm{~cm}^{-1}(\mathrm{NH}$ in-plane bending vibration of the benzimidazolium ion) in the IRSEC spectra of $\mathbf{2}$ and $\mathbf{4}$ (Figure $\mathbf{5} \mathbf{A}$ and $\mathbf{B}$ ) indicates the presence of products associated with only one proton transfer (EPT products). In the model described below, this observation will be taken as evidence that the equilibrium between the EPT and E2PT products is a function of the electron withdrawing/donating character of the R group.
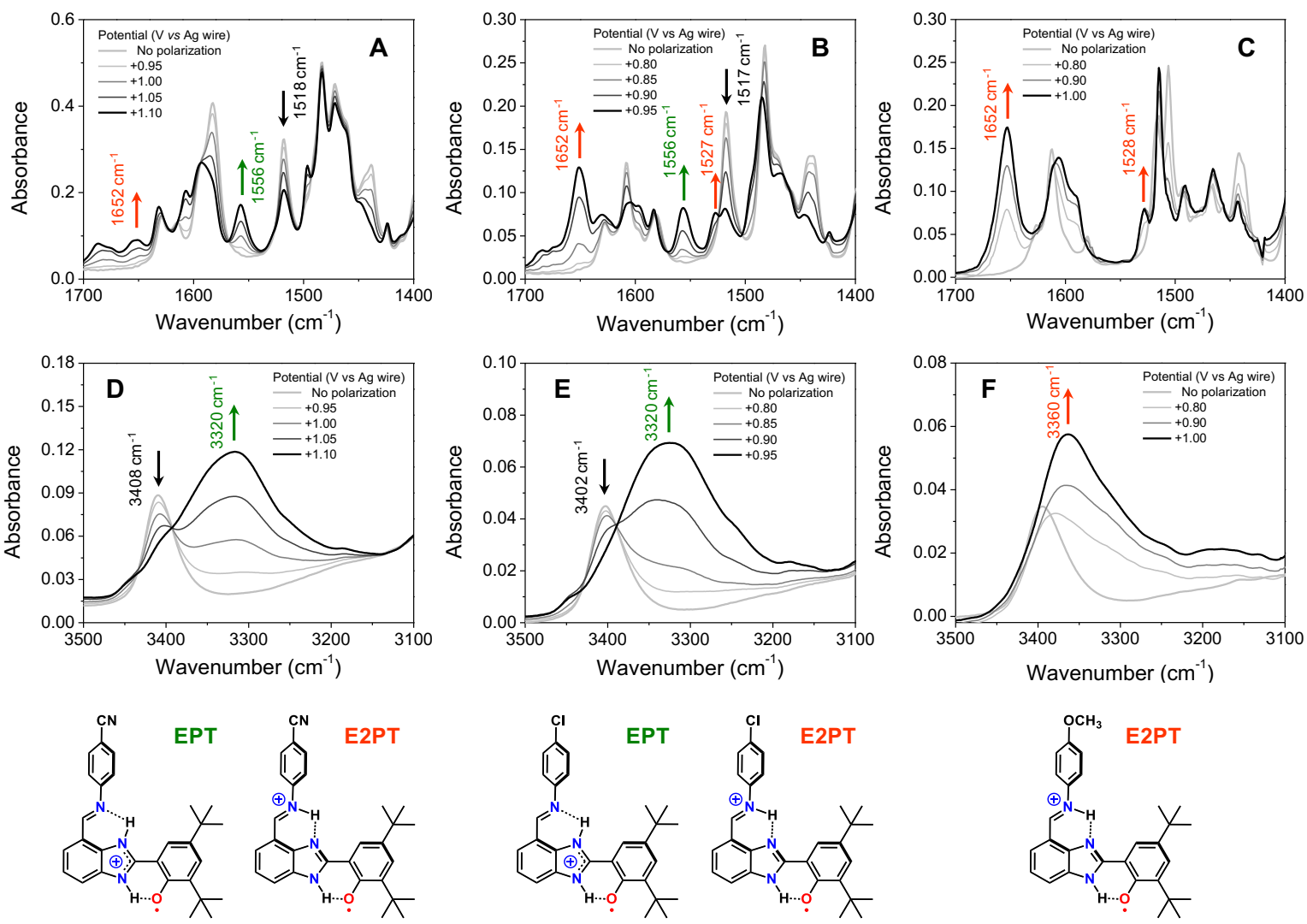

Figure 5. (A, B, C) IRSEC spectra of 2, 4 and 7, respectively, (19 mM) polarized in $50 \mathrm{mV}$ or $100 \mathrm{mV}$ increments to generate increasing amounts of the phenoxyl radical from the neutral phenol species, in the $1700-1400 \mathrm{~cm}^{-1}$ region. (D, E, F) IRSEC spectra of 2, 4 and 7, respectively, under the same conditions in the $3500-3100 \mathrm{~cm}^{-1}$ region. Solvent: $\mathrm{CH}_{2} \mathrm{Cl}_{2}, 0.1 \mathrm{M}$ TBAPF . The bands characteristic of EPT and E2PT products are indicated with green and orange arrows, respectively. The structures at the bottom correspond to the oxidized EPT and E2PT products. 
Importantly, there is no band growing in at $1556 \mathrm{~cm}^{-1}$ in the IRSEC spectra of $\mathbf{7}$ (Figure $\mathbf{5} \mathbf{C}$ ), indicating that stable, detectable levels of the benzimidazolium ion do not form upon phenol oxidation in this case. In other words, oxidation of 7 results predominantly in formation of the E2PT product. As a control, the $1556 \mathrm{~cm}^{-1}$ band does not appear upon titration of $\mathrm{CH}_{2} \mathrm{Cl}_{2}$ solutions of 7 with $\mathrm{CF}_{3} \mathrm{COOH}$ (0.5-2 equivalents), which only protonates the imine nitrogen (see Figure S36). Following oxidation of the BIP-Ph ${ }^{\mathrm{R} i m i n e s}$, the ratio of EPT and E2PT products formed as a function of the para-substituent (R-group) on the $N$-phenylimine moiety can also be analyzed by monitoring the imidazole $\mathrm{NH}$ stretching band $\left(v_{\mathrm{NH}}\right)$ (Figure 5 D, E and F). In the neutral species, the $v_{\mathrm{NH}}$ appears at $3408 \mathrm{~cm}^{-1}, 3402 \mathrm{~cm}^{-1}$, and $3394 \mathrm{~cm}^{-1}$ for 2,4 and 7 , respectively. The decrease in the $v_{\mathrm{NH}}$ compared to $1\left(v_{\mathrm{NH}}\right.$ at $3414 \mathrm{~cm}^{-1}$ ) is most likely due to the intramolecular $\mathrm{H}$ bond between the $\mathrm{NH}$ of the benzimidazole moiety and the imine nitrogen lone pair in the BIP- $\mathrm{Ph}^{\mathrm{R}}$ imines. Moreover, the progressive shift to lower frequencies supports the increasing $\mathrm{H}$-bond strength due to the increase in the electron-donating character of the para-substituents, consistent with the trend observed in the ${ }^{1} \mathrm{H}$ NMR (see $\delta_{\mathrm{NH}}$, Figure 2).

The changes observed in the spectra under electrochemical polarization are clearly different among the $\mathrm{BIP}-\mathrm{Ph}^{\mathrm{R}}$ imines. In the case of compounds $\mathbf{2}$ and $\mathbf{4}$ (Figure $\mathbf{5} \mathbf{D}$ and $\mathbf{E}$ ), the intensity of the $v_{\mathrm{NH}}$ band progressively decreases, and a broad NH stretching band of the benzimidazolium ion at $\sim 3320 \mathrm{~cm}^{-1}$ appears. ${ }^{33}$ This band is considerably broader than it was in the IRSEC of $\mathbf{1}$, as expected by the contribution of the E2PT product (protonated imine with $v_{\mathrm{NH}}$ at $\sim 3360$ $\mathrm{cm}^{-1}$ ). A clear isosbestic point at $\sim 3390 \mathrm{~cm}^{-1}$ was detected in the case of $\mathbf{2}$ and $\mathbf{4}$. In contrast, there is no indication of an isosbestic point for $\mathbf{7}$ (Figure $\mathbf{5}$ F). In this case, a new band for $v_{\mathrm{NH}}$ appears at $3360 \mathrm{~cm}^{-1}$ and an increase in intensity and width were observed. The absence of the marker benzimidazolium NH stretching band provides additional evidence that the EPT product cannot be detected in 7 . The changes of the bands in the region around 1528-1506 cm-1 observed in the IRSEC of 2, 4 and 7 are also consistent with the assignments of the E2PT and EPT products described above (see description and spectral assignments in SI, page S66-S68).

Scheme 1 is used to interpret the results of the IRSEC experiments for the series of $\mathrm{BIP}-\mathrm{Ph}^{\mathrm{R}}$ imines 2, 3, 4 and 7. Under thin film electrolysis conditions, we postulate that oxidation of $\mathbf{A}$ (a generic BIP-Ph ${ }^{\mathrm{R} i m i n e}$ ) produces $\mathbf{B}$ and $\mathbf{C}$, which are in equilibrium with each other as shown. In addition to the processes forming $\mathbf{B}$ and $\mathbf{C}$ labeled EPT and E2PT in Scheme 1, the proton transfer reaction templated by the $\mathrm{H}$-bond between the imidazole proton and the imine nitrogen in A can also lead to formation of an E2PT product arising from EPT followed by proton transfer, or an EPT product arising from E2PT followed by back proton transfer. Our experimental and computational data do not address the contributions of these pathways to the equilibrium between $\mathbf{B}$ and $\mathbf{C}$. Nonetheless, the results show, the dominant product switches from the E2PT species (C) in the case of $\mathbf{7}$ to an EPT species (B) when the basicity of the imine is reduced by functionalization with electron-withdrawing groups (e.g., $\mathrm{CN}$ and $-\mathrm{CF}_{3}$ in $\mathbf{2}$ and $\mathbf{3}$, respectively). Compound 4 represents an intermediate case where both $\mathbf{B}$ and $\mathbf{C}$ products are present in similar proportions following oxidation (Figure 5 B). As mentioned previously, in the IRSEC experiments the absorption bands at $1556 \mathrm{~cm}^{-1}$ and $1652 \mathrm{~cm}^{-1}$ provide spectroscopic indicators for detecting species $\mathbf{B}$ and $\mathbf{C}$, respectively. The intensities of these bands were assumed to be proportional to the concentrations of these species (BIP$\mathrm{COOCH}_{3}$ in its protonated state was shown to follow Beer's law at $1556 \mathrm{~cm}^{-1}$ over concentration ranges relevant to the experiments, and it is assumed that the radical species of Scheme 1 will also follow the law).

\section{Scheme 1. PCET Products of BIP-PhRimines Detected by IRSEC $a$}
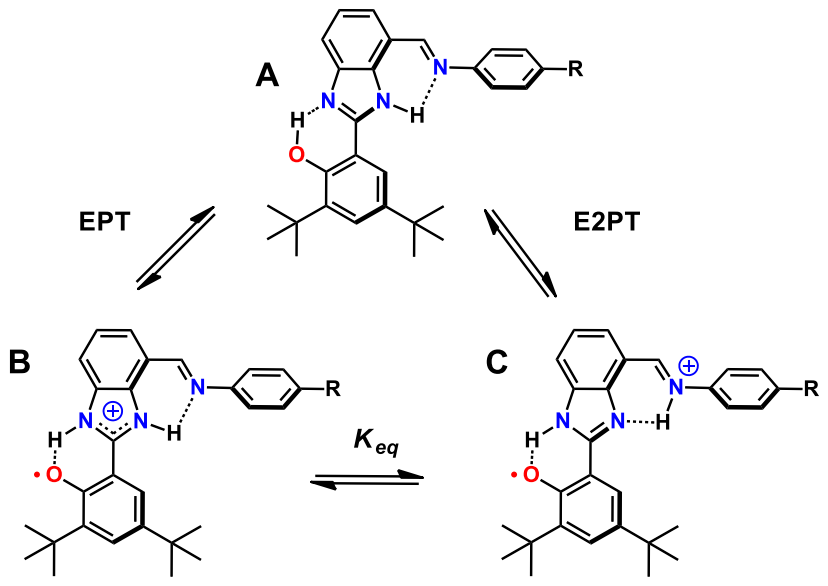

${ }^{a}$ From the IRSEC experiments with A, the EPT and E2PT products (B and $\mathbf{C}$, respectively) were identified when the working electrode was polarized positive of the associated phenoxyl radical/phenol redox couple. Following polarization, $\mathbf{B}$ and $\mathbf{C}$ products are present in equilibrium and at concentrations that are stable on the time scale of the measurements.

From the IRSEC data described above, the extinction coefficient for the band at $1652 \mathrm{~cm}^{-1}$ in 7 was used as an approximate value for the extinction coefficient of the $1652 \mathrm{~cm}^{-1}$ band present in the E2PT products of 2, 3 and 4 ( $C$ in Scheme 1) and in deriving the concentrations of the E2PT products following oxidation in each case. For each system, subtracting the concentration of the E2PT product from the initial concentration of the respective BIP-Ph${ }^{\mathrm{R} i m i n e}$ starting material (A in Scheme 1) yields the concentration of the EPT product (B in Scheme 1) and the equilibrium constant, $K_{e q}=[\mathrm{E} 2 \mathrm{PT}] /[\mathrm{EPT}]$, associated with interconversion between the EPT and E2PT oxidation products (Table 3 ).

The plot of $\Delta G^{0}$ derived from these values follows the expected linear Hammett relationship (Figure 6). Because there was no detectible level of the EPT product measured in the IRSEC of 7, the Hammett plot in Figure 6 was extrapolated as shown to give a $K_{e q}$ of 13.8 for 7. Using this value of $K_{e q}$, in conjunction with the $E_{1 / 2}$ value measured for the E2PT process of 7 , the $E_{1 / 2}$ value associated with the EPT process of 7 was determined to be $1.00 \mathrm{~V}$ vs SCE in $\mathrm{CH}_{3} \mathrm{CN}$ 
(1.02 V vs SCE in $\mathrm{CH}_{2} \mathrm{Cl}_{2}$ ). Because the EPT and E2PT processes involve the breaking and forming of different numbers and types of bonds, the EPT redox potentials were calculated using an isodesmic scheme with this $E_{1 / 2}$ value associated with the EPT process of $\mathbf{7}$ as a reference (see pages S74-S76). This scheme was used to calculate the $E_{1 / 2}$ values for the EPT processes shown in Table 2 and Figure 4. Table 3 shows the experimental and calculated equilibrium constants and corresponding $\Delta G^{0}$ for the four compounds studied using IRSEC. Negative $\Delta G^{0}$ values indicate that the E2PT product is thermodynamically more favorable than the EPT product, as is the case for compounds with electron-donating substituents such as $-\mathrm{OCH}_{3}$.

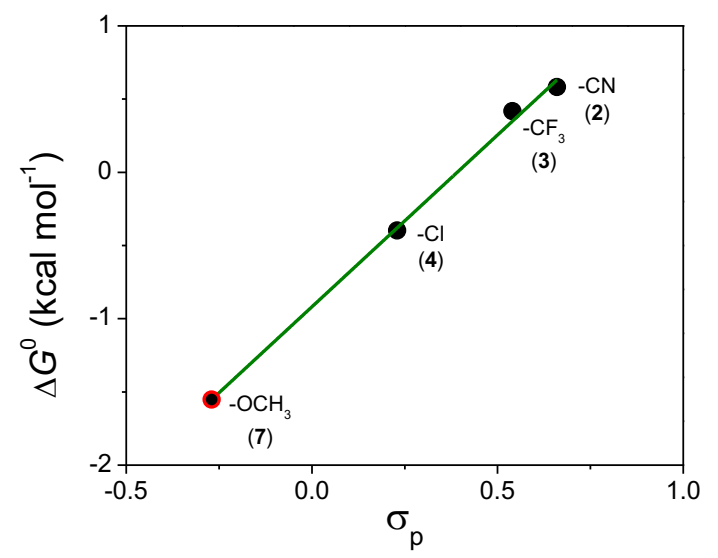

Figure 6. Experimentally determined free energy differences between E2PT and EPT products formed upon oxidation of the BIP-PhRimines $v s$ the $\sigma_{\mathrm{p}}$ for each of the BIP- $\mathrm{Ph}^{\mathrm{R}} \mathrm{imines}$. The point at the lower left for $\mathbf{7}$ (black circle with red outline) is obtained by extrapolating the line from the experimental values of 2,3 and $4(\mathrm{R}=0.98)$. Note that $\Delta G^{0}$ crosses from negative to positive values between 3 and $\mathbf{4}$.

Table 3. Free Energy Differences and Equilibrium Constants for the E2PT and EPT Products ${ }^{a}$

\begin{tabular}{lcccc}
\hline \hline \multirow{2}{*}{ Compound } & \multicolumn{2}{c}{$\Delta G^{0}(\mathrm{kcal} / \mathrm{mol})$} & \multicolumn{2}{c}{$K_{\text {eq }}$} \\
& Exp. & Calc. & Exp. & Calc. \\
\hline 2: $\mathrm{BIP}-\mathrm{Ph}^{\mathrm{CN}}$ imine & 0.6 & 0.5 & 0.4 & 0.4 \\
3: $\mathrm{BIP}-\mathrm{Ph}^{\mathrm{CF}}$ imine & 0.4 & 0.5 & 0.5 & 0.5 \\
4: $\mathrm{BIP}-\mathrm{Ph}^{\mathrm{Cl}}$ imine & -0.4 & -0.2 & 2.0 & 1.5 \\
7: $\mathrm{BIP}-\mathrm{Ph}^{\mathrm{OCH}_{3}}$ imine & -1.6 & $-1.6^{b}$ & 13.8 & $13.8^{b}$ \\
\hline \hline
\end{tabular}

$a$ The values reported herein were experimentally measured and calculated in $\mathrm{CH}_{2} \mathrm{Cl}_{2}$. An analogous table for the calculations performed in $\mathrm{CH}_{3} \mathrm{CN}$ is provided in Table $\mathrm{S} 18$.

$b$ The EPT and E2PT redox potentials for $\mathbf{7}$ were used as the reference reactions, and therefore the experimental and calculated values agree by construction.
On the other hand, with electron-withdrawing substituents such as $-\mathrm{CF}_{3}$ and $-\mathrm{CN}$, the situation is reversed, and the positive values of $\Delta G^{0}$ indicate that the EPT products are thermodynamically more favorable. This trend is also shown in Figure 4, where the calculated $E_{1 / 2}$ values associated with EPT processes fall below those associated with the corresponding E2PT processes at more positive Hammett constants.

KIE. Experimental KIE values were determined electrochemically for BIP- $\mathrm{Ph}^{\mathrm{R} i m i n e s}$ 2, 3, 4 and 7 and are reported in Table 4. As can be seen, the KIE values are close to 1.0 and are in line with previously reported values for related systems. ${ }^{33}$ These previous calculations employed a vibronically nonadiabatic PCET theory, ${ }^{25,69-71}$ which may be viewed as an extension of Marcus theory for electron transfer ${ }^{72}$ with the transferring proton, as well as the electrons, treated quantum mechanically to allow simultaneous electron and proton tunneling. In this PCET theory, the overall rate constant is computed as the sum of the individual rate constants associated with pairs of reactant and product electron-proton vibronic states, weighted by the Boltzmann population of the reactant state. Each individual rate constant for a pair of reactant/product vibronic states depends exponentially on the free energy barrier and is proportional to the square of the vibronic coupling, which is the product of the electronic coupling and the overlap integral between the reactant and product proton vibrational wavefunctions. In the context of this PCET theory, the KIE of around unity is explained in terms of significant contributions from excited electron-proton vibronic states. The proton vibrational wavefunctions associated with these excited states are more delocalized and therefore can lead to larger overlap integrals within the vibronic coupling. As discussed elsewhere, ${ }^{25,71}$ greater overlap integrals between the reactant and product proton vibrational wavefunctions typically lead to lower KIEs that can approach unity.

Table 4. Experimental Kinetic Isotope Effects

\begin{tabular}{lc}
\hline \hline \multicolumn{1}{c}{ Compound } & KIE \\
\hline 2: $\mathrm{BIP}-\mathrm{Ph}^{\mathrm{CN}}$ imine & $1.2 \pm 0.3$ \\
3: $\mathrm{BIP}-\mathrm{Ph}^{\mathrm{CF}}$ imine & $1.3 \pm 0.3$ \\
4: $\mathrm{BIP}-\mathrm{Ph}^{\mathrm{Cl}}$ imine & $1.1 \pm 0.3$ \\
7: $\mathrm{BIP}-\mathrm{Ph}^{\mathrm{OCH}_{3}}$ imine & $1.1 \pm 0.3$ \\
\hline \hline
\end{tabular}

In previous studies on related systems, we observed that BIP compounds exhibiting only the E2PT product have KIEs $\sim 1$, while related compounds exhibiting only the EPT product have larger KIEs ( $>1.5$ ), with the exception of porphyrinbound BIPs. ${ }^{33}$ Accordingly, in the present series compound 7 yields predominantly the E2PT product, and the electrochemically measured KIE is $\sim 1$. The other compounds, 2, 3 and 4, form both EPT and E2PT products, with EPT dominating for electron-withdrawing substituents such as -CN and $-\mathrm{CF}_{3}$ in $\mathbf{2}$ and $\mathbf{3}$, respectively. Even though a tendency toward larger KIE values for the formation of EPT products 
is apparent in these compounds, the error bars make it impossible to use KIE data as a definitive predictor between the EPT and E2PT mechanisms.

\section{Conclusion}

The BIP-Ph ${ }^{\mathrm{R} i m i n e s}$ are bioinspired, reversible, hole-transporting artificial photosynthetic model relays that exhibit proton translocation over $\sim 6 \AA$. This series illustrates formation of both EPT and E2PT products upon electrochemical oxidation of the phenol. From spectroelectrochemical and theoretical data we conclude that the ratio of E2PT to EPT products following oxidation can be modulated by the nature of the substituents on the BIP-PhRimines. Strong electron-withdrawing groups such as $-\mathrm{CN}$ and $-\mathrm{CF}_{3}$ decrease both the $\mathrm{H}$-bond strength and the imine nitrogen basicity; thus, the second proton transfer is less thermodynamically favored and the EPT product is dominant. Conversely, the stronger electron-donating group - $\mathrm{OCH}_{3}$ increases both the $\mathrm{H}$-bond strength and the imine nitrogen basicity, and the E2PT product is the dominant species upon oxidation. An intermediate situation is achieved using the - $\mathrm{Cl}$ substituent, where a mixture of both oxidized species corresponding to EPT and E2PT processes was observed. We found experimentally only a slight change in the phenol redox potential, 0.99 to $0.93 \mathrm{~V}$ vs SCE, between the compounds that yield predominantly the EPT products and those that yield mainly the E2PT products.

These findings are relevant in the context of designing artificial photosynthetic assemblies given that the previously reported amino-substituted BIPs with redox potentials $\sim 0.6 \mathrm{~V}$ vs SCE would not be able to act as a relay in water oxidation at near-neutral $\mathrm{pH} .{ }^{32}$ In contrast, BIP-Ph ${ }^{\mathrm{R} i m i n e}$ derivatives that conserve the high phenol redox potential, close to $1.0 \mathrm{~V} v s \mathrm{SCE}$, would be thermodynamically capable of acting as redox relays in water oxidation schemes resembling natural photosynthesis. The different behaviors of the imino- and amino-substituted BIPs arise from a balance among the relative $\mathrm{p} K \mathrm{a}$ values, the $\mathrm{H}$-bond strengths, and the midpoint potential of the phenoxyl radical/phenol couple. The experimental and computational work herein explores the delicate balance among these factors in favoring either the EPT or the E2PT process and in tuning the associated redox potentials.

It is important to emphasize that because the EPT and E2PT products are in equilibrium, endergonic steps $(K<1)$ do not preclude the transport of protons over a H-bond network. Just as electrons can be transferred over endergonic steps in redox reactions in electron transport chains, ${ }^{73}$ proton transport over endergonic steps could occur as long as the final step is exergonic with respect to the initial PCET process. Certainly, a future challenge in biomimicry is efficient net proton transfer, which will require a molecular design in which the PCET site is "reloaded" with a new proton after each oxidation.

The results from these model systems provide insight into the role played by PCET and the Tyrz-His190 relay of PSII in water oxidation and management of proton activity around the energy-coupling thylakoid membrane of plants, algae, and cyanobacteria. This work also demonstrates that the exquisite control over proton activity, a feature common to all bioenergetic systems, can be explored in artificial constructs, where it can lead to design principles for efficient solar energy conversion in artificial photosynthesis.

\section{ASSOCIATED CONTENT}

Supporting Information. It includes experimental and computational results. Experimental: synthesis and structural characterization, NMR data, X-ray data, electrochemical measurements, IRSEC, IR data and KIE determination. Computational: electronic structure calculations, calculation of redox potentials, analysis of the thermodynamics of PCET reactions, computed IRSEC spectra and band assignment and optimized cartesian coordinates of species studied. This material is available free of charge via the Internet at http://pubs.acs.org.

\section{AUTHOR INFORMATION}

\section{Corresponding Author}

*E-mail: gary.f.moore@asu.edu.

*E-mail: sharon.hammes-schiffer@yale.edu.

*E-mail: amoore@asu.edu.

\section{ORCID}

Emmanuel Odella: 0000-0002-7021-400X

S. Jimena Mora: 0000-0003-4181-4732

Brian L. Wadsworth: 0000-0002-0274-9993

Mioy T. Huynh: 0000-0002-0472-7624

Joshua J. Goings: 0000-0002-2817-1966

Miguel Gervaldo: 0000-0001-9287-5872

Leónides E. Sereno: 0000-0001-8361-7695

Devens Gust: 0000-0003-0550-8498

Thomas A. Moore: 0000-0002-1577-7117

Gary F. Moore: 0000-0003-3369-9308

Sharon Hammes-Schiffer: 0000-0002-3782-6995

Ana L. Moore: 0000-0002-6653-9506

\section{Author Contributions}

‡These authors contributed equally.

Notes

The authors declare no competing financial interest.

\section{ACKNOWLEDGMENT}

This research was supported by the U.S. Department of Energy, Office of Science, Office of Basic Energy Sciences, under Award DE-FG02-03ER15393. The theoretical portion of this research was supported by the Center for Molecular Electrocatalysis, which is an Energy Frontier Research Center funded by the U.S. Department of Energy, Office of Science, Office of Basic Energy Sciences.

\section{REFERENCES}

(1) Umena, Y.; Kawakami, K.; Shen, J.-R.; Kamiya, N. Crystal Structure of Oxygen-Evolving Photosystem II at a Resolution of 1.9 Å. Nature 2011, 473, 55-60.

(2) Suga, M.; Akita, F.; Sugahara, M.; Kubo, M.; Nakajima, Y.; Nakane, T.; Yamashita, K.; Umena, Y.; Nakabayashi, M.; Yamane, T.; 
Nakano, T.; Suzuki, M.; Masuda, T.; Inoue, S.; Kimura, T.; Nomura, T.; Yonekura, S.; Yu, L.-J.; Sakamoto, T.; Motomura, T.; Chen, J.-H.; Kato, Y.; Noguchi, T.; Tono, K.; Joti, Y.; Kameshima, T.; Hatsui, T.; Nango, E.; Tanaka, R.; Naitow, H.; Matsuura, Y.; Yamashita, A.; Yamamoto, M.; Nureki, O.; Yabashi, M.; Ishikawa, T.; Iwata, S.; Shen, J.-R. Light-Induced Structural Changes and the Site of $0=0$ Bond Formation in PSII Caught by XFEL. Nature 2017, 543, 131-135.

(3) Barry, B. A.; Babcock, G. T. Tyrosine Radicals Are Involved in the Photosynthetic Oxygen-Evolving System. Proc. Natl. Acad. Sci. 1987, 84, 7099-7103.

(4) Tommos, C.; Babcock, G. T. Proton and Hydrogen Currents in Photosynthetic Water Oxidation. Biochim. Biophys. Acta - Bioenerg. 2000, 1458, 199-219.

(5) Blankenship, R. E. Molecular Mechanisms of Photosynthesis, Second Ed.; Wiley Blackwell: Oxford, UK, Hoboken, NJ, USA, 2014.

(6) Yano, J.; Yachandra, V. $\mathrm{Mn}_{4} \mathrm{Ca}$ Cluster in Photosynthesis: Where and How Water Is Oxidized to Dioxygen. Chem. Rev. 2014, 114, 4175-4205.

(7) Mora, S. J.; Odella, E.; Moore, G. F.; Gust, D.; Moore, T. A.; Moore, A. L. Proton-Coupled Electron Transfer in Artificial Photosynthetic Systems. Acc. Chem. Res. 2018, 51, 445-453.

(8) Keough, J. M.; Jenson, D. L.; Zuniga, A. N.; Barry, B. A. Proton Coupled Electron Transfer and Redox-Active Tyrosine $\mathrm{Z}$ in the Photosynthetic Oxygen-Evolving Complex. J. Am. Chem. Soc. 2011, 133, 11084-11087.

(9) Rappaport, F.; Boussac, A.; Force, D. A.; Peloquin, J.; Brynda, M.; Sugiura, M.; Un, S.; Britt, R. D.; Diner, B. A. Probing the Coupling between Proton and Electron Transfer in Photosystem II Core Complexes Containing a 3-Fluorotyrosine. J. Am. Chem. Soc. 2009, 131, 4425-4433.

(10) Young, K. J.; Brennan, B. J.; Tagore, R.; Brudvig, G. W. Photosynthetic Water Oxidation: Insights from Manganese Model Chemistry. Acc. Chem. Res. 2015, 48, 567-574.

(11) Vinyard, D. J.; Brudvig, G. W. Progress Toward a Molecular Mechanism of Water Oxidation in Photosystem II. Annu. Rev. Phys. Chem. 2017, 68, 101-116.

(12) Migliore, A.; Polizzi, N. F.; Therien, M. J.; Beratan, D. N. Biochemistry and Theory of Proton-Coupled Electron Transfer. Chem. Rev. 2014, 114, 3381-3465.

(13) Stubbe, J.; Nocera, D. G.; Yee, C. S.; Chang, M. C. Y. Radical Initiation in the Class I Ribonucleotide Reductase: Long-Range Proton-Coupled Electron Transfer? Chem. Rev. 2003, 103, 21672202.

(14) Chaves, I.; Pokorny, R.; Byrdin, M.; Hoang, N.; Ritz, T.; Brettel, K.; Essen, L.-O.; van der Horst, G. T. J.; Batschauer, A.; Ahmad, M. The Cryptochromes: Blue Light Photoreceptors in Plants and Animals. Annu. Rev. Plant Biol. 2011, 62, 335-364.

(15) Gray, H. B.; Winkler, J. R. Hole Hopping through Tyrosine/Tryptophan Chains Protects Proteins from Oxidative Damage. Proc. Natl. Acad. Sci. 2015, 112, 10920-10925.

(16) Blomberg, M. R. A. Mechanism of Oxygen Reduction in Cytochrome c Oxidase and the Role of the Active Site Tyrosine. Biochemistry 2016, 55, 489-500.

(17) Mathes, T.; van Stokkum, I. H. M.; Stierl, M.; Kennis, J. T. M. Redox Modulation of Flavin and Tyrosine Determines Photoinduced Proton-Coupled Electron Transfer and Photoactivation of BLUF Photoreceptors. J. Biol. Chem. 2012, 287, 31725-31738.

(18) Markle, T. F.; Rhile, I. J.; DiPasquale, A. G.; Mayer, J. M. Probing Concerted Proton-Electron Transfer in Phenol-Imidazoles. Proc. Natl. Acad. Sci. 2008, 105, 8185-8190.

(19) Rhile, I. J.; Markle, T. F.; Nagao, H.; DiPasquale, A. G.; Lam, O. P.; Lockwood, M. A.; Rotter, K.; Mayer, J. M. Concerted Proton-Electron Transfer in the Oxidation of Hydrogen-Bonded Phenols. J. Am. Chem. Soc. 2006, 128, 6075-6088.
(20) Glover, S. D.; Parada, G. A.; Markle, T. F.; Ott, S.; Hammarström, L. Isolating the Effects of the Proton Tunneling Distance on Proton-Coupled Electron Transfer in a Series of Homologous Tyrosine-Base Model Compounds. J. Am. Chem. Soc. 2017, 139, 2090-2101.

(21) Barry, B. A. Reaction Dynamics and Proton Coupled Electron Transfer: Studies of Tyrosine-Based Charge Transfer in Natural and Biomimetic Systems. Biochim. Biophys. Acta - Bioenerg. 2015, 1847, 46-54.

(22) Gagliardi, C. J.; Vannucci, A. K.; Concepcion, J. J.; Chen, Z.; Meyer, T. J. The Role of Proton Coupled Electron Transfer in Water Oxidation. Energy Environ. Sci. 2012, 5, 7704-7717.

(23) Savéant, J.-M. Electrochemical Approach to ProtonCoupled Electron Transfers: Recent Advances. Energy Environ. Sci. 2012, 5, 7718-7731.

(24) Carra, C.; Iordanova, N.; Hammes-Schiffer, S. ProtonCoupled Electron Transfer in a Model for Tyrosine Oxidation in Photosystem II. J. Am. Chem. Soc. 2003, 125, 10429-10436.

(25) Hammes-Schiffer, S. Proton-Coupled Electron Transfer: Moving Together and Charging Forward. J. Am. Chem. Soc. 2015, $137,8860-8871$.

(26) Schrauben, J. N.; Cattaneo, M.; Day, T. C.; Tenderholt, A. L.; Mayer, J. M. Multiple-Site Concerted Proton-Electron Transfer Reactions of Hydrogen-Bonded Phenols Are Nonadiabatic and Well Described by Semiclassical Marcus Theory. J. Am. Chem. Soc. 2012, 134, 16635-16645.

(27) Bowring, M. A.; Bradshaw, L. R.; Parada, G. A.; Pollock, T. P.; Fernández-Terán, R. J.; Kolmar, S. S.; Mercado, B. Q.; Schlenker, C. W.; Gamelin, D. R.; Mayer, J. M. Activationless Multiple-Site Concerted Proton-Electron Tunneling. J. Am. Chem. Soc. 2018, 140, 7449-7452.

(28) Benisvy, L.; Bittl, R.; Bothe, E.; Garner, C. D.; McMaster, J.; Ross, S.; Teutloff, C.; Neese, F. Phenoxyl Radicals Hydrogen-Bonded to Imidazolium: Analogues of Tyrosyl D• of Photosystem II: HighField EPR and DFT Studies. Angew. Chemie Int. Ed. 2005, 44, 53145317.

(29) Megiatto, J. D.; Antoniuk-Pablant, A.; Sherman, B. D.; Kodis, G.; Gervaldo, M.; Moore, T. A.; Moore, A. L.; Gust, D. Mimicking the Electron Transfer Chain in Photosystem II with a Molecular Triad Thermodynamically Capable of Water Oxidation. Proc. Natl. Acad. Sci. 2012, 109, 15578-15583.

(30) Moore, G. F.; Hambourger, M.; Kodis, G.; Michl, W.; Gust, D.; Moore, T. A.; Moore, A. L. Effects of Protonation State on a Tyrosine-Histidine Bioinspired Redox Mediator. J. Phys. Chem. B 2010, 114, 14450-14457.

(31) Chararalambidis, G.; Das, S.; Trapali, A.; Quaranta, A.; Orio, M.; Halime, Z.; Fertey, P.; Guillot, R.; Coutsolelos, A.; Leibl, W.; Aukauloo, A.; Sircoglou, M. Water Molecules Gating a Photoinduced One-Electron Two-Protons Transfer in a Tyrosine/Histidine (Tyr/His) Model of Photosystem II. Angew. Chemie Int. Ed. 2018, 57, 9013-9017.

(32) Zhao, Y.; Swierk, J. R.; Megiatto, J. D.; Sherman, B.; Youngblood, W. J.; Qin, D.; Lentz, D. M.; Moore, A. L.; Moore, T. A.; Gust, D.; Mallouk, T. E. Improving the Efficiency of Water Splitting in Dye-Sensitized Solar Cells by Using a Biomimetic Electron Transfer Mediator. Proc. Natl. Acad. Sci. 2012, 109, 15612-15616.

(33) Huynh, M. T.; Mora, S. J.; Villalba, M.; Tejeda-Ferrari, M. E.; Liddell, P. A.; Cherry, B. R.; Teillout, A.-L.; Machan, C. W.; Kubiak, C. P.; Gust, D.; Moore, T. A.; Hammes-Schiffer, S.; Moore, A. L. Concerted One-Electron Two-Proton Transfer Processes in Models Inspired by the Tyr-His Couple of Photosystem II. ACS Cent. Sci. 2017, 3, 372-380.

(34) Vosko, S. H.; Wilk, L.; Nusair, M. Accurate SpinDependent Electron Liquid Correlation Energies for Local Spin Density Calculations: A Critical Analysis. Can. J. Phys. 1980, 58, 1200-1211. 
(35) Lee, C.; Yang, W.; Parr, R. G. Development of the ColleSalvetti Correlation-Energy Formula into a Functional of the Electron Density. Phys. Rev. B 1988, 37, 785-789.

(36) Becke, A. D. Density-Functional Thermochemistry. III. The Role of Exact Exchange. J. Chem. Phys. 1993, 98, 5648-5652.

(37) Stephens, P. J.; Devlin, F. J.; Ashvar, C. S.; Chabalowski, C. F.; Frisch, M. J. Theoretical Calculation of Vibrational Circular Dichroism Spectra. Faraday Discuss. 1994, 99, 103-119.

(38) Hehre, W. J.; Ditchfield, R.; Pople, J. A. Self-Consistent Molecular Orbital Methods. XII. Further Extensions of GaussianType Basis Sets for Use in Molecular Orbital Studies of Organic Molecules. J. Chem. Phys. 1972, 56, 2257-2261.

(39) Hariharan, P. C.; Pople, J. A. The Influence of Polarization Functions on Molecular Orbital Hydrogenation Energies. Theor. Chim. Acta 1973, 28, 213-222.

(40) Barone, V.; Cossi, M. Quantum Calculation of Molecular Energies and Energy Gradients in Solution by a Conductor Solvent Model. J. Phys. Chem. A 1998, 102, 1995-2001.

(41) Cossi, M.; Rega, N.; Scalmani, G.; Barone, V. Energies, Structures, and Electronic Properties of Molecules in Solution with the C-PCM Solvation Model. J. Comput. Chem 2003, 24, 669-681.

(42) Frisch, M. J.; Trucks, G. W.; Schlegel, H. B.; Scuseria, G. E.; Robb, M. A.; Cheeseman, J. R.; Scalmani, G.; Barone, V.; Petersson, G. A.; Nakatsuji, H.; Li, X.; Caricato, M.; Marenich, A.; Bloino, J.; Janesko, B. G.; Gomperts, R.; Mennucci, B.; Hratchian, H. P.; Ortiz, J. V.; Izmaylov, A. F.; Sonnenberg, J. L.; Williams-Young, D.; Ding, F.; Lipparini, F.; Egidi, F.; Goings, J.; Peng, B.; Petrone, A.; Henderson, T.; Ranasinghe, D.; Zakrzewski, V. G.; Gao, J.; Rega, N.; Zheng, G.; Liang, W.; Hada, M.; Ehara, M.; Toyota, K.; Fukuda, R.; Hasegawa, J.; Ishida, M.; Nakajima, T.; Honda, Y.; Kitao, O.; Nakai, H.; Vreven, T.; Throssell, K.; Montgomery Jr., J. A.; Peralta, J. E.; Ogliaro, F.; Bearpark, M.; Heyd, J. J.; Brothers, E.; Kudin, K. N.; Staroverov, V. N.; Keith, T.; Kobayashi, R.; Normand, J.; Raghavachari, K.; Rendell, A.; Burant, J. C.; Iyengar, S. S.; Tomasi, J.; Cossi, M.; Millam, J. M.; Klene, M.; Adamo, C.; Cammi, R.; Ochterski, J. W.; Martin, R. L.; Morokuma, K.; Farkas, O.; Foresman, J. B.; Fox, D. J. Gaussian 09 Revision D.01. Gaussian, Inc: Wallingford, CT 2013.

(43) Preston, P. N. Synthesis, Reactions, and Spectroscopic Properties of Benzimidazoles. Chem. Rev. 1974, 74, 279-314.

(44) Megiatto Jr, J. D.; Méndez-Hernández, D. D.; TejedaFerrari, M. E.; Teillout, A.-L.; Llansola-Portolés, M. J.; Kodis, G.; Poluektov, O. G.; Rajh, T.; Mujica, V.; Groy, T. L.; Gust, D.; Moore, T. A.; Moore, A. L. A Bioinspired Redox Relay That Mimics Radical Interactions of the Tyr-His Pairs of Photosystem II. Nat. Chem. 2014, 6, 423-428.

(45) Moore, G. F.; Hambourger, M.; Gervaldo, M.; Poluektov, O. G.; Rajh, T.; Gust, D.; Moore, T. A.; Moore, A. L. A Bioinspired Construct That Mimics the Proton Coupled Electron Transfer between P680 + and the Tyrz-His190 Pair of Photosystem II. J. Am. Chem. Soc. 2008, 130, 10466-10467.

(46) Morales, S.; Guijarro, F. G.; García Ruano, J. L.; Cid, M. B. A General Aminocatalytic Method for the Synthesis of Aldimines. J. Am. Chem. Soc. 2014, 136, 1082-1089.

(47) Connelly, N. G.; Geiger, W. E. Chemical Redox Agents for Organometallic Chemistry. Chem. Rev. 1996, 96, 877-910.

(48) Machan, C. W.; Sampson, M. D.; Chabolla, S. A.; Dang, T.; Kubiak, C. P. Developing a Mechanistic Understanding of Molecular Electrocatalysts for $\mathrm{CO}_{2}$ Reduction Using Infrared Spectroelectrochemistry. Organometallics 2014, 33, 4550-4559.

(49) Zavarine, I. S.; Kubiak, C. P. A Versatile Variable Temperature Thin Layer Reflectance Spectroelectrochemical Cell. J. Electroanal. Chem. 2001, 495, 106-109.

(50) Nicholson, R. S. Theory and Application of Cyclic Voltammetry for Measurement of Electrode Reaction Kinetics. Anal. Chem. 1965, 37, 1351-1355.

(51) Bard, A. J.; Faulkner, L. R. Electrochemical Methods: Fundamentals and Applications, 2nd ed.; Wiley: New York, 2001.
(52) Hansch, C.; Leo, A.; Taft, R. W. A Survey of Hammett Substituent Constants and Resonance and Field Parameters. Chem. Rev. 1991, 91, 165-195.

(53) Chen, G.; Cao, C.; Lu, B.; Sheng, B. The Substituent Effect on the UV Energy of 4,4'-Disubstituted Benzylideneanilines. J. Phys. Org. Chem. 2012, 25, 327-333.

(54) Reeves, R. L.; Smith, W. F. The Protonation of Benzylideneaniline and Its $\mathrm{p}$ - and $\mathrm{p}$ '-Dimethylamino Derivatives. J. Am. Chem. Soc. 1963, 85, 724-728.

(55) Fang, Z.; Wu, F.; Yi, B.; Cao, C.; Xie, X. Effects of Molecular Conformation on the Spectroscopic Properties of $4,4^{\prime}$ Disubstituted Benzylideneanilines. J. Mol. Struct. 2016, 1104, 5257.

(56) Cao, C.-T.; Bi, Y.; Cao, C. Effects of Single Bond-Ion and Single Bond-Diradical Form on the Stretching Vibration of CN Bridging Bond in 4,4'-Disubstituted Benzylidene Anilines. Spectrochim. Acta Part A Mol. Biomol. Spectrosc. 2016, 163, 96-101.

(57) Wang, L.; Cao, C.; Cao, C. Comparison of the Substituent Effects on the ${ }^{13} \mathrm{C}$ NMR with the ${ }^{1} \mathrm{H}$ NMR Chemical Shifts of $\mathrm{CH}=\mathrm{N}$ in Substituted Benzylideneanilines. Magn. Reson. Chem. 2015, 53, 520-525.

(58) Weinstein, J.; McIninch, E. Base Strengths of p Substituted Benzalanilines. J. Am. Chem. Soc. 1960, 82, 6064-6067.

(59) Khoo, L. E. Azomethine Proton Chemical Shift of Schiff Bases. Spectrochim. Acta Part A Mol. Spectrosc. 1979, 35, 993-995.

(60) Katsumi, T.; Etsurou, S. The Nuclear Magnetic Resonance and Infrared Spectra of Aromatic Azomethines. Bull. Chem. Soc. Jpn. 1969, 42, 1440-1443.

(61) Güner, V.; Bayari, S. Infrared Spectra and AM1 Calculations of N-Benzylideneanilines. Spectrosc. Lett. 2002, 35, 83-98.

(62) Kozhevina, L. I.; Prokopenko, E. B.; Rybachenko, V. I.; Titov, E. V. The Vibrational Spectra and Force Constants of Benzylideneaniline and Its Fluoroderivatives. J. Mol. Struct. 1993, $295,53-72$.

(63) Figueroa, K.; Campos-Vallette, M.; Rey-Lafon, M. Vibrational Study of p, p '-Disubstituted N-Benzylideneanilines. Spectrochim. Acta Part A Mol. Spectrosc. 1990, 46, 1659-1665.

(64) Meic, Z.; Baranovic, G. Vibrational Spectra of Trans-NBenzylideneaniline and Its Isotopomers. Pure Appl. Chem. 1989, 61, 2129-2138.

(65) Lussier, L. S.; Sandorfy, C.; L E-Thanh, H. O.; Vocelle, D. The Effect of Acids on the Infrared Spectra of Schiff Bases. II. Imines Containing the $\mathrm{C}=\mathrm{C}-\mathrm{C}=\mathrm{N}$ and $\mathrm{C}=\mathrm{C}-\mathrm{C}=\mathrm{C}-\mathrm{C}=\mathrm{N}$ Units. Photochem. Photobiol. 1987, 45, 801-808.

(66) Baasov, T.; Friedman, N.; Sheves, M. Factors Affecting the $\mathrm{C}=\mathrm{N}$ Stretching in Protonated Retinal Schiff Base: A Model Study for Bacteriorhodopsin and Visual Pigments. Biochemistry 1987, 26, 3210-3217.

(67) López-Garriga, J. J.; Babcock, G. T.; Harrison, J. F. Factors Influencing the $\mathrm{C}=\mathrm{N}$ Stretching Frequency in Neutral and Protonated Schiff's Bases. J. Am. Chem. Soc. 1986, 108, 7241-7251.

(68) López-Garriga, J. J.; Hanton, S.; Babcock, G. T.; Harrison, J. F. Rehybridization of the $\mathrm{C}=\mathrm{N}$ Bond upon Protonation of Methylimine Increases the $\mathrm{C}=\mathrm{N}$ Stretching Force Constant. J. Am. Chem. Soc. 1986, 108, 7251-7254.

(69) Soudackov, A.; Hammes-Schiffer, S. Derivation of Rate Expressions for Nonadiabatic Proton-Coupled Electron Transfer Reactions in Solution. J. Chem. Phys. 2000, 113, 2385-2396.

(70) Soudackov, A.; Hatcher, E.; Hammes-Schiffer, S. Quantum and Dynamical Effects of Proton Donor-Acceptor Vibrational Motion in Nonadiabatic Proton-Coupled Electron Transfer Reactions. J. Chem. Phys. 2005, 122, 014505.

(71) Hammes-Schiffer, S.; Soudackov, A. V. Proton-Coupled Electron Transfer in Solution, Proteins, and Electrochemistry. J. Phys. Chem. B 2008, 112, 14108-14123. 
(72) Marcus, R. A.; Sutin, N. Electron Transfers in Chemistry and Biology. Biochim. Biophys. Acta - Rev. Bioenerg. 1985, 811, 265322.
(73) Page, C. C.; Moser, C. C.; Chen, X.; Dutton, P. L. Natural Engineering Principles of Electron Tunnelling in Biological Oxidation-reduction. Nature 1999, 402, 47-52. 


\section{TABLE OF CONTENTS (TOC)}

2

3

4

5

6

7

8

9

10

11

12

13

14

15

16

17

18

19

20

21

22

23

24

25

26

27

28

29

30

31

32

33

34

35

36

37

38

39

40

41

42

43

44

45

46

47

48

49

50

51

52

53

54

55

56

57

58

59

60

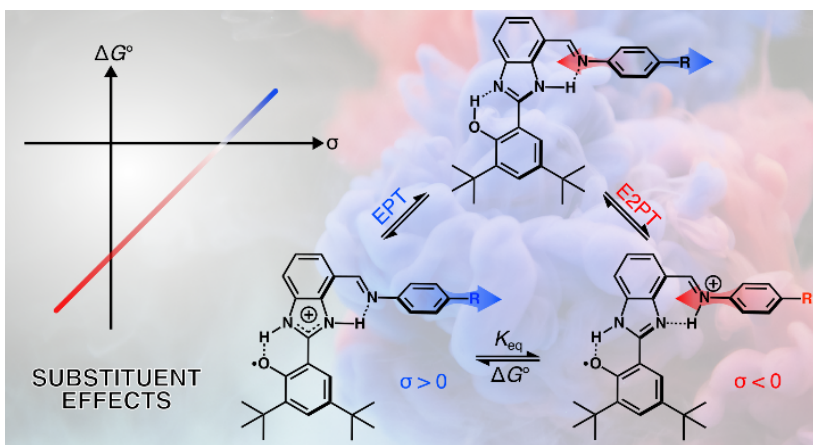

